Supporting Information

\title{
Quantitative in vitro-to-in vivo extrapolation: nominal versus freely dissolved concentration
}

\author{
Luise Henneberger, ${ }^{1 *}$ Julia Huchthausen, ${ }^{1}$ Niklas Wojtysiak, ${ }^{1}$ Beate I. Escher, ${ }^{1,2}$ \\ ${ }^{1}$ Department of Cell Toxicology, Helmholtz Centre for Environmental Research - UFZ, \\ Permoserstr. 15, DE-04318 Leipzig, Germany \\ ${ }^{2}$ Environmental Toxicology, Center for Applied Geoscience, Eberhard Karls University \\ Tübingen, Schnarrenbergstr. 94-96, DE-72076 Tübingen, Germany
}

\section{Table of contents}

Table S1. Examples calculation for QIVIVE $_{\text {nom }}$ and QIVIVE free $_{\text {ratios. }}$

Table S2. Liquid chromatography (LC) parameters of the test chemicals.

Table S3. Mass spectrometry (MS) parameters of the test chemicals.

Figure $\mathrm{S} 1$. Specificity ratios of the nominal $\left(\mathrm{SR}_{\mathrm{nom}}\right)$ and freely dissolved effect concentrations $\left(\mathrm{SR}_{\text {free }}\right)$ and classification according to Escher et al. (2020). 
Table S1. Examples calculation for QIVIVE nom $_{\text {and }}$ QIVIVE free ratios.

Scenario 1 assumes that the chemical is stable in the in vitro bioassay, scenario 2 that the chemical is degraded during the assay, resulting in a reduction of the total medium concentration.

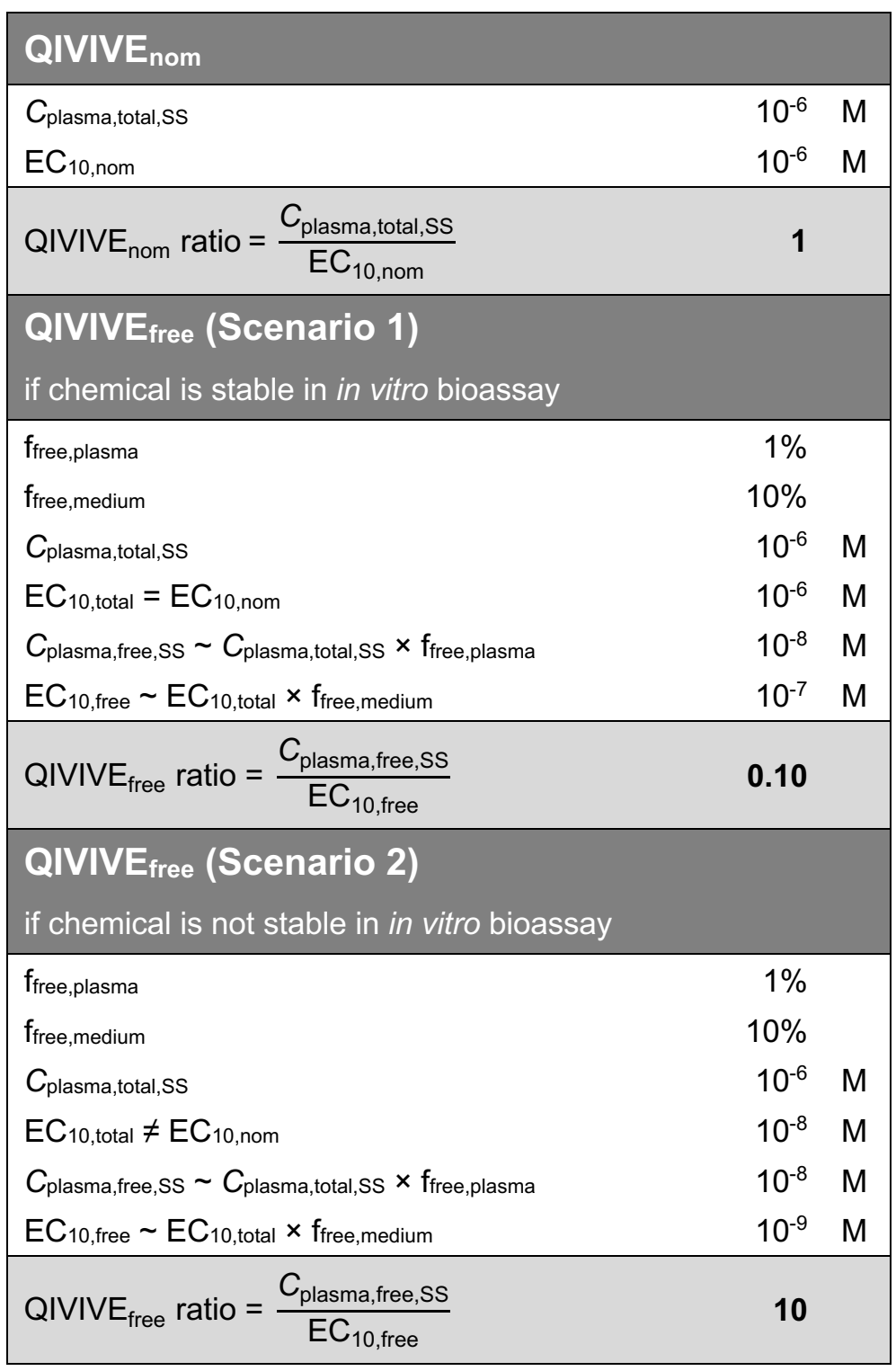

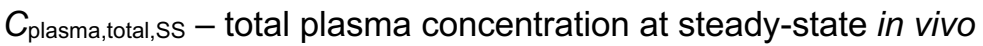

$\mathrm{EC}_{10, \text { nom }}$ - nominal effect concentration from in vitro bioassay

$f_{\text {free,plasma }}$ - free fraction in plasma

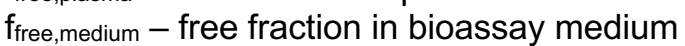

$\mathrm{EC}_{10 \text {,total }}$ - effect concentration from in vitro bioassay expressed as total medium concentration

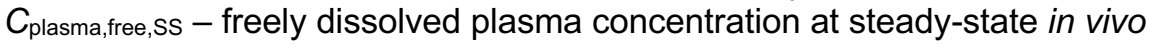

$\mathrm{EC}_{10 \text {,free }}$ - freely dissolved effect concentration from in vitro bioassay 
Table S2. Liquid chromatography (LC) parameters of the test chemicals.

Chemicals were separated using a Phenomenex Kinetex C18 column $(1.7 \mu \mathrm{m}, 50 \times 2.1 \mathrm{~mm})$ at $40^{\circ} \mathrm{C}$. A flow rate of $0.5 \mathrm{~mL} / \mathrm{min}$ was applied. Solvent C - $5 \%$ acetonitrile $95 \%$ water with $0.1 \%$ formic acid, Solvent D - $95 \%$ acetonitrile $5 \%$ water with $0.1 \%$ formic acid.

\begin{tabular}{lccc}
\hline Chemical & Solvent & $\begin{array}{c}\text { Injection volume } \\
{[\mu l]}\end{array}$ & $\begin{array}{c}\text { Limit of quantification } \\
\text { (LOQ) }[\mathrm{ng} / \mathrm{mL}]\end{array}$ \\
\hline Naproxen & $55 \%$ Solvent C 45 \% Solvent D & PBS: 2, Extracts: 15 & PBS: 10, Extracts: 5 \\
Ibuprofen & $45 \%$ Solvent C 55\% Solvent D & 5 & 50 \\
Telmisartan & $65 \%$ Solvent C 35\% Solvent D & 1 & 1 \\
Labetalol & $83 \%$ Solvent C 17\% Solvent D & 1 & 5 \\
\hline
\end{tabular}

Table S3. Mass spectrometry (MS) parameters of the test chemicals.

\begin{tabular}{lccccccc}
\hline Chemical & $\begin{array}{c}\text { Ion } \\
\text { source }\end{array}$ & $\begin{array}{c}\text { FV } \\
{[\mathrm{V}]}\end{array}$ & MRM transitions $(\mathrm{CE}[\mathrm{V}])$ & $\begin{array}{c}\text { CV } \\
{[\mathrm{V}]}\end{array}$ & $\begin{array}{c}\text { GF } \\
{[\mathrm{ml} / \mathrm{min}]}\end{array}$ & $\begin{array}{c}\text { GT } \\
{\left[{ }^{\circ} \mathrm{C}\right]}\end{array}$ & $\begin{array}{c}\text { Neb } \\
{[\mathrm{psi}]}\end{array}$ \\
\hline Naproxen & ESI- & 80 & $229.08 \rightarrow 185 / 168.9(1 / 33)$ & 5000 & 13 & 290 & 25 \\
lbuprofen & ESI- & 80 & $205.12 \rightarrow 161.1(4)$ & 4000 & 13 & 320 & 25 \\
Telmisartan & ESI+ & 230 & $515 \rightarrow 497 / 276(38 / 40)$ & 2000 & 8 & 350 & 60 \\
Labetalol & ESI+ & 120 & $329.19 \rightarrow 311 / 91(8 / 36)$ & 2000 & 13 & 350 & 40 \\
\hline
\end{tabular}

$\mathrm{FV}$ - fragmentor voltage

$\mathrm{CE}$ - collision energy

$\mathrm{CV}$ - capillary voltage

GF - gas flow

GT - gas temperature

Neb - Nebulizer 
Figure S1. Specificity ratios of the nominal $\left(\mathrm{SR}_{\text {nom }}\right)$ and freely dissolved effect concentrations $\left(S R_{\text {free }}\right)$ and classification according to (Escher et al. 2020).

Filled symbols refer to $S R$ from experimental $I_{C_{10, n o m}}$ and experimental $\mathrm{EC}_{10, \text { nom }}$ (Huchthausen et al. 2020). Empty symbols indicate $S R_{\text {baseline }}$ calculated from predicted $I C_{10, \text { nom }}$ for baseline toxicity (Escher et al. 2019) and experimental $E C_{10, n o m}$ (Huchthausen et al. 2020).
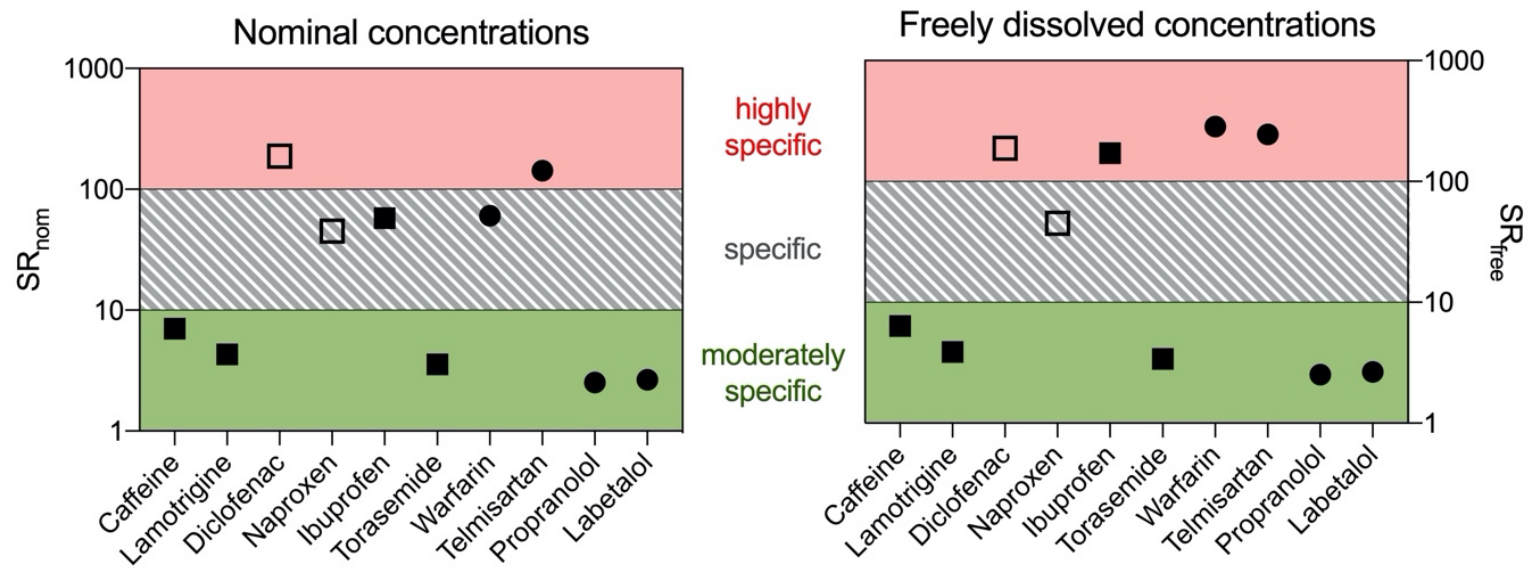

\section{References}

Escher BI, Glauch L, Konig M, Mayer P, Schlichting R. 2019. Baseline toxicity and volatility cutoff in reporter gene assays used for high-throughput screening. Chemical Research in Toxicology 32:16461655.

Escher BI, Henneberger L, Konig M, Schlichting R, Fischer FC. 2020. Cytotoxicity burst? Differentiating specific from nonspecific effects in tox21 in vitro reporter gene assays. Environ Health Perspect 128:77007.

Huchthausen, J.; Muhlenbrink, M.; Konig, M.; Escher, B. I.; Henneberger, L. 2020. Experimental Exposure Assessment of Ionizable Organic Chemicals in In Vitro Cell-Based Bioassays. Chemical Research in Toxicology 33 (7): 1845-1854. 